TITLE:

\title{
Gold(I)-Catalyzed Oxidative Cascade Cyclization of 1,4-Diyn-3- ones for the Construction of Tropone-Fused Furan Scaffolds
}

\section{$\operatorname{AUTHOR(S):~}$}

Hamada, Naoka; Yamaguchi, Ayuta; Inuki, Shinsuke; Oishi, Shinya; Ohno, Hiroaki

\section{CITATION:}

Hamada, Naoka ...[et al]. Gold(I)-Catalyzed Oxidative Cascade Cyclization of 1,4-Diyn-3ones for the Construction of Tropone-Fused Furan Scaffolds. Organic Letters 2018, 20(15): 4401-4405

\section{ISSUE DATE:}

2018-08-03

URL:

http://hdl.handle.net/2433/241630

\section{RIGHT:}

This document is the Accepted Manuscript version of a Published Work that appeared in final form in 'Organic Letters', copyright ( ) American Chemical Society after peer review and technical editing by the publisher. To access the final edited and published work see https://doi.org/10.1021/acs.orglett.8b01524.; The full-text file will be made open to the public on 23 July 2019 in accordance with publisher's 'Terms and Conditions for Self-Archiving'.; This is not the published version. Please cite only the published version.; この論文は出版社版でありません。引用の際には出版社版 をご確認ご利用ください。 


\title{
Gold(I)-Catalyzed Oxidative Cascade Cyclization of 1,4-Diyn-3-ones for the Construction of Tropone-Fused Furan Scaffolds
}

\author{
Naoka Hamada, Ayuta Yamaguchi, Shinsuke Inuki, Shinya Oishi, and Hiroaki Ohno* \\ Graduate School of Pharmaceutical Sciences, Kyoto University, Sakyo-ku, Kyoto 606-8501, Japan \\ Supporting Information Placeholder
}

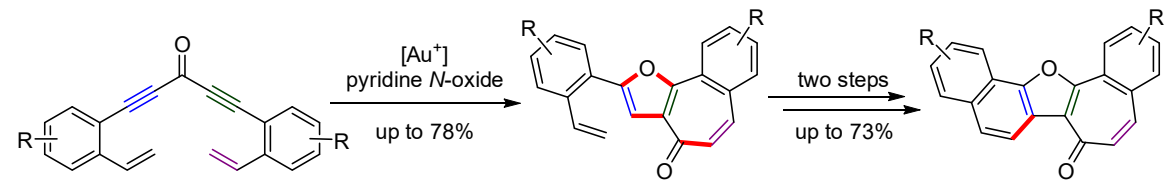

ABSTRACT: Gold(I)-catalyzed cascade cyclization of 1,4-diyn-3-ones with a pyridine $N$-oxide enabled direct construction of a benzo[6,7]cyclohepta[1,2-b]furan scaffold with the formation of four bonds. This reaction would proceed through oxidative cyclization, alkynyl migration, and 5-endo-dig type cyclization. Synthesis of benzotropone-fused naphtho[1,2-b]furans through a two-step sequence, including epoxidation and $\operatorname{In}(\mathrm{OTf})_{3}$-catalyzed intramolecular carbon-carbon bond formation, is also presented.

Cascade reactions are a powerful method for increasing molecular complexity in a single operation from readily available starting materials. ${ }^{1}$ In particular, gold-catalyzed cascade reactions of $1, n$-diynes are useful strategies for the synthesis of various carbocycles and heterocycles. ${ }^{2}$ Highly reactive intermediates are generated in these reactions, which facilitate further transformations, such as cyclopropanation, ring expansion, nucleophilic addition, $\mathrm{C}-\mathrm{H}$ bond insertion, and cycloaddition, to give polycyclic products. It has been well established that goldcatalyzed oxidation of alkynes with a pyridine oxide derivative forms a highly electrophilic $\alpha$-oxo gold carbenoid species, avoiding the use of potentially explosive diazo compounds. ${ }^{3}$ The generated $\alpha$-oxo gold carbenoids undergo a variety of transformations to produce various types of cyclic products. For example, in 2011, Liu's group reported an intramolecular cyclopropanation of 1,5-enynes for the synthesis of cyclopropanefused indanone derivatives ${ }^{4}$ (Scheme 1A). Hashmi et al. developed a gold-catalyzed furan formation reaction using 1,4-diyn3 -ol or 3-amine derivatives, which proceeds through formation of $\alpha$-oxo gold carbenoid and 1,2-alkynyl migration (Scheme 1B). ${ }^{5}$ Zhang's group reported cyclopentanone formation using $\mathrm{C}-\mathrm{H}$ insertion as the termination step, through oxidation of ynone-type substrates (Scheme 1C). ${ }^{6}$ In this reaction, the two acyl groups are assumed to provide steric hindrance to suppress intermolecular side reactions of the highly electrophilic gold carbenoid species.

\section{Scheme 1. Previous Work and Concept of This Work}

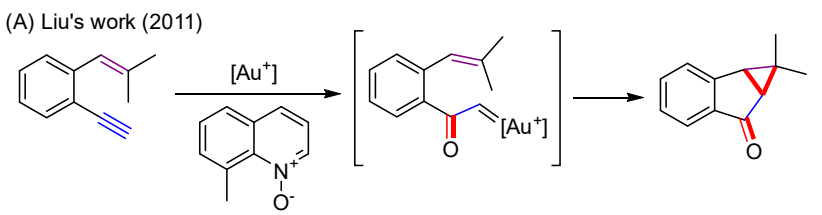

(B) Hashmi's work (2014)<smiles>[R]C#CC([Y19])C#C[R]</smiles>

(C) Zhang's work (2015)

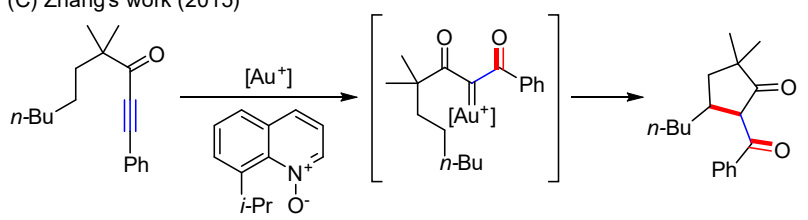

(D) this work: gold(I)-catalyzed oxidative cyclization of 1,4-diyn-3-one

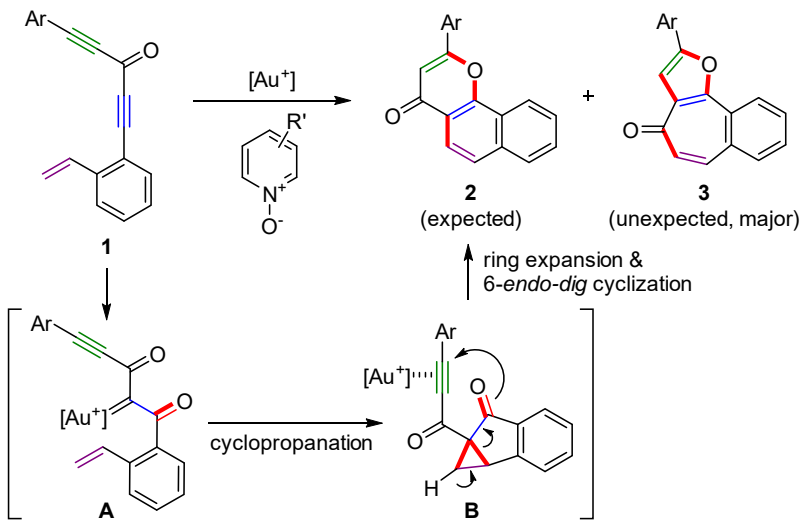


Herein, we report an oxidative cascade cyclization of 1,4diyn-3-ones bearing alkene moieties 1 to produce benzotropone-fused furan derivatives 3 (Scheme 1D). Our initial expectation was that a gold catalyst would activate 1,4-diyn-3-ones 1 in the presence of a pyridine $N$-oxide to form $\beta$-diketone- $\alpha$-gold carbenoid intermediate $\mathbf{A}$, which would undergo cyclopropanation to give intermediate B bearing an ynone moiety. Subsequent activation of the other alkyne by the same gold catalyst would facilitate 6-endo-dig cyclization by the carbonyl group with ring expansion to give benzo[ $h]$ chromene 2 . Unexpectedly, we found that the major product was benzo[6,7]cyclohepta[1,2$b]$ furan 3, although formation of the chromene 2 was also observed depending on the reaction conditions. In this contribution, our efforts to examine this novel cyclization and its application to highly fused naphthofuran derivatives are presented.

\section{Table 1. Optimization of the Reaction Conditions}
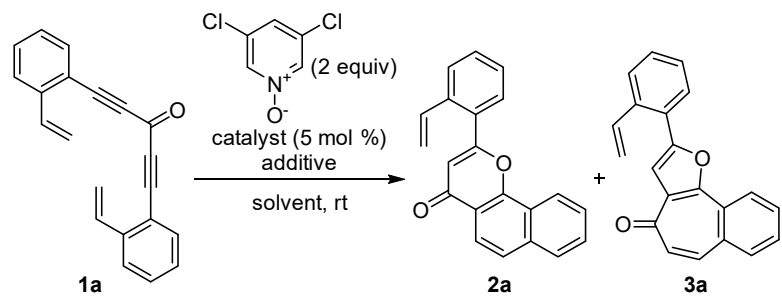

\begin{tabular}{|c|c|c|c|c|c|}
\hline \multirow{2}{*}{ entry } & \multirow{2}{*}{ catalyst } & \multirow{2}{*}{$\begin{array}{l}\text { additive } \\
\text { (equiv) }\end{array}$} & \multirow{2}{*}{ solvent $(\mathrm{M})$} & \multicolumn{2}{|c|}{ yield $(\%)^{a}$} \\
\hline & & & & $2 a$ & 3a \\
\hline 1 & $\begin{array}{l}\text { BrettPhos- } \\
\text { AuNTf }_{2}\end{array}$ & - & DCE (0.05) & 15 & $-^{b}$ \\
\hline 2 & $\begin{array}{l}\text { JohnPhos- } \\
\text { AuNTf }_{2}\end{array}$ & - & DCE (0.05) & $10^{c}$ & $17^{c}$ \\
\hline 3 & $\mathrm{PPh}_{3} \mathrm{AuNTf}_{2}$ & - & DCE (0.05) & trace & trace \\
\hline 4 & $\mathrm{IPrAuNTf}_{2}$ & - & DCE $(0.05)$ & - & 28 \\
\hline 5 & $\mathrm{IPrAuNTf}_{2}$ & $\operatorname{HFIP}^{d}(10)$ & DCE $(0.05)$ & - & 42 \\
\hline 6 & IPrAuNTf $_{2}$ & HFIP (10) & DCE (0.1) & - & 77 \\
\hline 7 & $\mathrm{IPrAuNTf}_{2}$ & HFIP (10) & $\operatorname{DCE}(0.2)$ & - & 63 \\
\hline 8 & $\mathrm{IPrAuNTf}_{2}$ & HFIP (10) & toluene $(0.1)$ & - & 31 \\
\hline 9 & $\mathrm{IPrAuNTf}_{2}$ & HFIP (10) & EtOH (0.1) & - & - \\
\hline 10 & $\mathrm{IPrAuNTf}_{2}$ & - & $\operatorname{HFIP}(0.1)$ & - & 38 \\
\hline
\end{tabular}

${ }^{a}$ Isolated yields. ${ }^{b}$ Not detected. ${ }^{c}$ Determined by ${ }^{1} \mathrm{H}$ NMR analysis and combined yield of $\mathbf{2 a}$ and $\mathbf{3 a} .{ }^{d} \mathrm{HFIP}=$ hexafluoropropan2-ol.
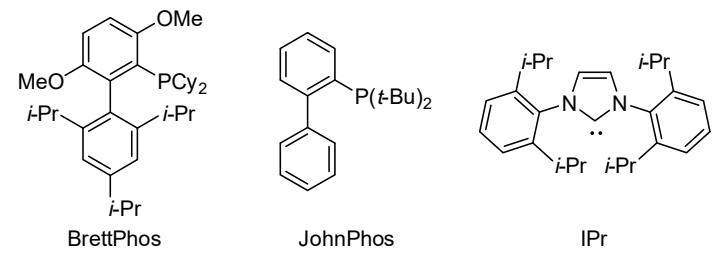

JohnPhos

$\operatorname{IPr}$

At the outset, we chose the diynone 1a bearing two alkene moieties as the substrate to avoid any regioselectivity issues between the two alkynes (Table 1). The reaction of 1a with 3,5dichloropyridine $N$-oxide in the presence of $5 \mathrm{~mol} \%$ of BrettPhosAuNTf 2 gave the expected benzo[h]chromene 2a in

$15 \%$ yield (entry 1 ). Use of JohnPhosAuNTf $f_{2}$ or $\mathrm{PPh}_{3} \mathrm{AuNTf}_{2}$ as the catalyst gave the tropone-fused furan, benzo[6,7]cyclohepta[1,2-b]furan derivative 3a, along with 2a (entries 2, 3). The structures of $\mathbf{2 a}$ (CCDC 1827398) and 3a (CCDC 1827399) were confirmed by X-ray crystallography (Figure 1). When using IPrAuNTf 2 as the catalyst, the tropone-fused furan 3a was formed in $28 \%$ yield without formation of benzo[ $h]$ chromene 2a (entry 4). A possible explanation for the observed ligand effects would be that the electronically poor nature of the IPr gold complex might be inappropriate for activation of the triple bond of ynone $\mathbf{B}$ to facilitate the cyclization to 2 (Scheme 1). Further screening of the reaction conditions to obtain $\mathbf{3 a}$ as the major product was conducted, and to our delight, the addition of 10 equiv of hexafluoropropan-2-ol (HFIP) gave $3 \mathbf{a}$ in $42 \%$ yield (entry 5). Gevorgyan's group recently reported that 1,4-diyn-3ones can undergo a 1,3-transposition to produce 2,4-diyn-1ones (isomerization from skipped diynes to conjugated ones) in the presence of gold catalysts. ${ }^{7}$ To accelerate the desired intermolecular reaction with the pyridine $N$-oxide over other reactions, including the intramolecular 1,3-transposition, we next focused our attention on the influence of the substrate concentrations. Indeed, more concentrated conditions $(0.1 \mathrm{M} 1 \mathrm{a})$ led to a significant improvement in the yield of tropone $\mathbf{3 a}(77 \%$, entry 6$)$, while further concentration was ineffective $(0.2 \mathrm{M} \mathrm{1a}$; $63 \%$, entry 7). Finally, several other solvents were tested in the reaction, including toluene, EtOH, and HFIP (entries 8-10); however, all these solvents resulted in a decreased yield of $\mathbf{3 a}$ or inhibited the reaction (EtOH, entry 9).

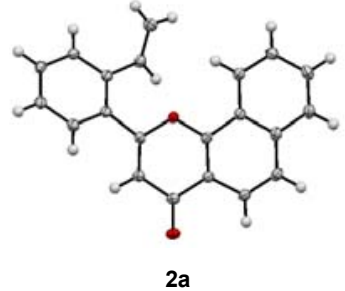

Figure 1. X-ray structures of $2 \mathrm{a}$ and $3 a$.

With the optimized conditions in hand (Table 1, entry 6), we investigated the scope of the reaction using a variety of substrates (Scheme 2). 1,4-Diyn-3-one 1b, bearing electron-donating methoxy groups at the 4-position of the both phenyl groups, smoothly underwent the desired reaction to afford the corresponding tropone-fused furan $\mathbf{3 b}$ in $78 \%$ yield. Halogen substituents at the 4-position were also tolerated in this reaction to provide 3c, although the yield was relatively low (49\%). The substituents at the 5-position (meta-position to alkyne) slightly decreased the yields of the furan 3 . For example, 1,4-diyn-3-ones 1d and 1e with electron-donating methoxy or methyl groups gave $3 \mathbf{d}$ and $3 \mathbf{e}$ in $52 \%$ and $63 \%$ yields, whereas the 5-chlorinated substrate 1f showed a similar reactivity to the 4-chlorinated one to afford $\mathbf{3 f}$ in $48 \%$ yield. Diynone $1 \mathrm{~g}$ with 3,4-dimethoxyphenyl groups showed good reactivity, resulting in a $71 \%$ isolated yield of $\mathbf{3 g}$. Introduction of fused benzene rings into the substrate afforded the corresponding tetracyclic fused tropone derivatives $3 \mathbf{h}$ and $\mathbf{3 i}$ in moderate yields $(56 \%$ and $45 \%$, respectively). Finally, 1,4-diyn-3-one $\mathbf{1 j}$ bearing isopropenyl groups at the 2-position (instead of vinyl groups) was tested, and methylated tropone derivative $\mathbf{3 j}$ was obtained in good yield (67\%). 
Scheme 2. Substrate Scope ${ }^{a}$
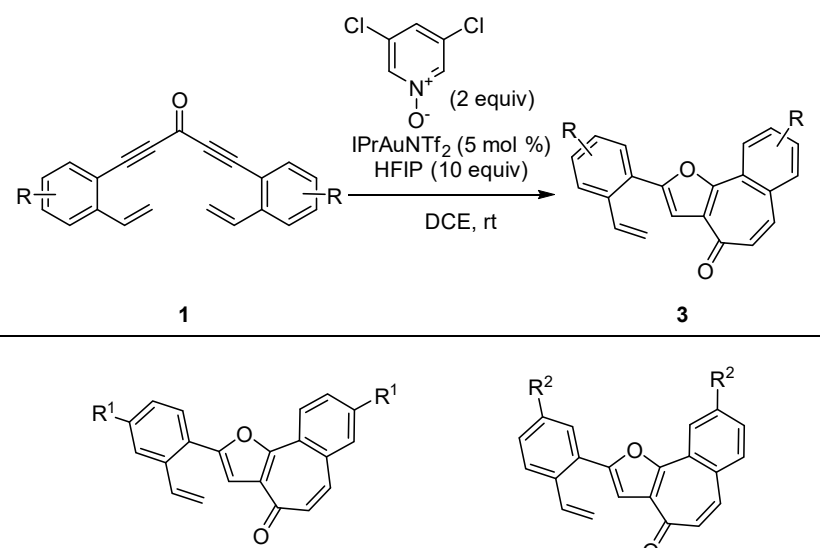

3a: $\mathrm{R}^{1}=\mathrm{H}(77 \%)$

3b: $\mathrm{R}^{1}=$ OMe $(78 \%)$

3c: $\mathrm{R}^{1}=\mathrm{Cl}(49 \%)$

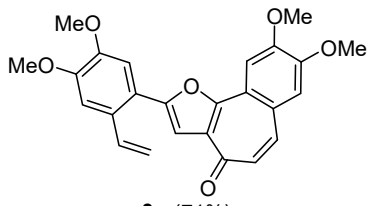

3 g $(71 \%)$

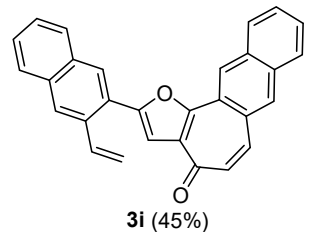

$3 \mathbf{i}(45 \%)$

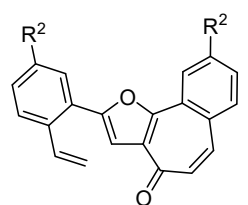

3d: $R^{2}=$ OMe $(52 \%)$

3e: $R^{2}=\operatorname{Me~}(63 \%)$

3f: $R^{2}=\mathrm{Cl}(48 \%)$

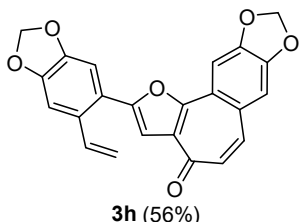

3h (56\%)

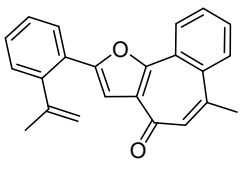

3j (67\%)

${ }^{a}$ Isolated yields.

Our mechanistic proposal for the cascade reactions is depicted in Scheme 3. As reported by Zhang and co-workers, ${ }^{6} \beta$ diketone- $\alpha$-gold carbenoid species A would be generated as the key reactive intermediate by gold-promoted oxidation of the ynone. There are then two possible mechanisms: through formation of a cyclopropane intermediate $\mathbf{B}$ (path a) or via benzyl cation intermediate $\mathbf{E}$ (path b). In path a, after cyclopropanation of the gold carbenoid with the vinyl group to give $\mathbf{B}$, ring expansion to cationic cyclobutane intermediate $\mathbf{C}$ would facilitate a 1,2-alkynyl shift ${ }^{5,8}$ to generate intermediate $\mathbf{D}$. The reaction is terminated by gold-catalyzed intramolecular 5-endo-dig cyclization to the other alkyne moiety, with ring expansion and subsequent protodeauration to produce the tropone-fused furan 3. In path $b$, the styrene moiety acts as a nucleophile to attack the carbonyl group of ynone $\mathbf{A}$ to give the benzyl cation intermediate E. Subsequently, a 1,2-alkynyl shift onto the gold carbenoid species ${ }^{5}$ would form a diketone intermediate F. Finally, 5-endo-dig cyclization followed by protodeauration gives the same fused furan $\mathbf{3}$ as path a. Since both pathways sufficiently rationalize the observed results, further experimental and theoretical studies are necessary for complete elucidation of the reaction mechanism.

We next focused on the application of the resulting furan derivatives to the synthesis of highly fused compounds. We expected that the remaining vinyl group in $\mathbf{3}$ could be efficiently used for the construction of an additional benzene ring. This strategy would lead to the construction of a fused naphthofuran motif, which is found not only in biologically active natural and synthetic products (Figure 2$)^{9}$ but also in fluorescent markers ${ }^{10}$ and electronic devices. ${ }^{11}$ Considering that Lewis acid catalyzed cyclization of ethylene oxide is one of the most efficient ways to synthesize fused aromatic molecules, ${ }^{12}$ we prepared epoxide $4 \mathbf{a}$ by treatment of $\mathbf{3} \mathbf{a}$ with oxone in the presence of $\mathrm{NaHCO}_{3}$ in a mixture of $\mathrm{CH}_{2} \mathrm{Cl}_{2} /$ acetone $/ \mathrm{H}_{2} \mathrm{O}$ (Scheme 4).

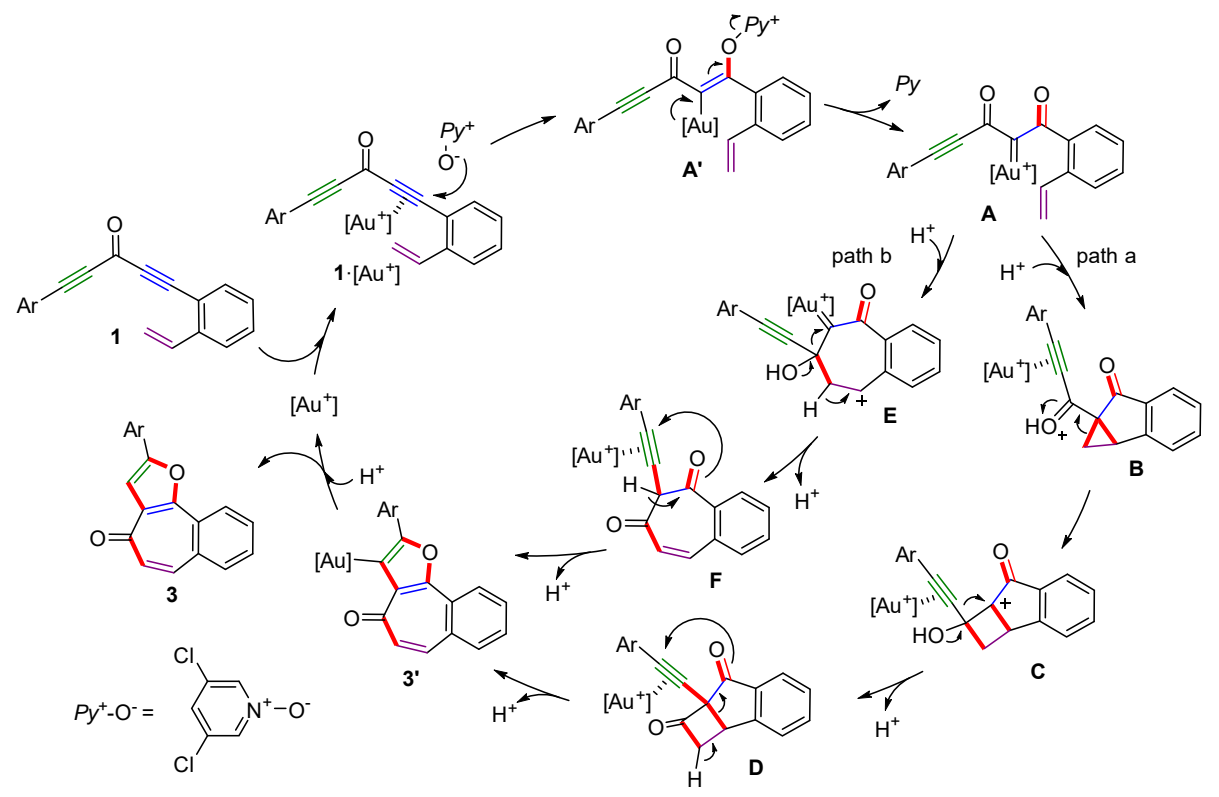

Scheme 3. Proposed Reaction Mechanisms 
<smiles>CC(=O)c1c(O)c2ccccc2c2occc12</smiles>

furomollugin

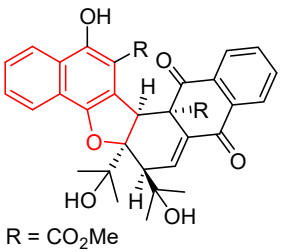

rubioncolin $\mathrm{A}$

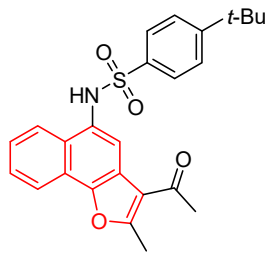

CX4152
Figure 2. Natural products and a bioactive compound bearing a naphthofuran moiety.

\section{Scheme 4. Epoxidation of 3a}<smiles>C=Cc1ccccc1-c1cc2c(=O)ccc3ccccc3c2o1</smiles>

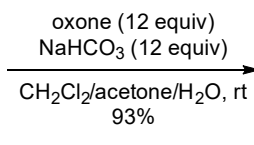

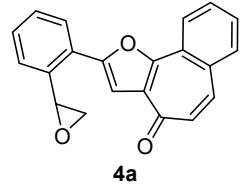

$4 a$
We then examined the cyclization of the epoxide $4 a$ with a Lewis acid (Table 3), which would facilitate the benzene ring construction by the sequence of the ring-opening of the epoxide, the 1,2-hydride shift to form aldehyde, and an intramolecular electrophilic aromatic substitution followed by dehydration. ${ }^{2 b}$ Fortunately, treatment of the epoxide $4 \mathbf{a}$ with 2 equiv of $\mathrm{ZnCl}_{2}$ in 1,2-DCE gave the desired highly fused naphthofuran $\mathbf{5 a}$ (CCDC 1827401), although in low yield (20\%, entry 1). After screening various Lewis acids (entries $2-5$ ), we found that the use of $\operatorname{In}(\mathrm{OTf})_{3}$ led to an increase in the yield of $\mathbf{5 a}(68 \%$, entry 5). A catalytic reaction using $20 \mathrm{~mol} \% \mathrm{In}(\mathrm{OTf})_{3}$ at an elevated temperature $\left(80^{\circ} \mathrm{C}\right)$ also produced $\mathbf{5 a}$ in $68 \%$ yield within $3 \mathrm{~h}$ (entry 7). To our delight, crude epoxide 4a (after simple workup) can be similarly used for the Lewis acid catalyzed cyclization, thus affording $\mathbf{5 a}$ in $64 \%$ yield in two steps from fused furan 3a.

Table 3. Optimization of the Reaction Conditions for the Lewis Acid Mediated Cyclization
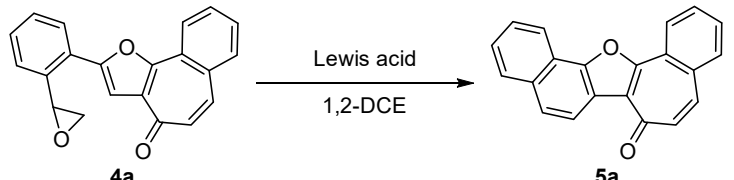

$\begin{array}{lllll}\text { entry } & \text { Lewis acid (equiv) } & \text { temp }\left({ }^{\circ} \mathrm{C}\right) & \text { time }(\mathrm{h}) & \text { yield }(\%)^{a} \\ 1 & \mathrm{ZnCl}_{2}(2) & 50 & 6 & 20 \\ 2 & \mathrm{FeCl}_{3}(2) & 50 & 6 & 38 \\ 3 & \operatorname{InCl}_{3}(2) & 50 & 6 & 56 \\ 4 & \operatorname{InBr}_{3}(2) & 50 & 4 & 61 \\ 5 & \operatorname{In}_{(\mathrm{OTf})}(2) & 50 & 4 & 68 \\ 6 & \mathrm{In}(\mathrm{OTf})_{3}(0.2) & 50 & 8 & 54 \\ 7^{b} & \mathbf{I n}(\mathbf{O T f})_{3}(\mathbf{0 . 2}) & \mathbf{8 0} & \mathbf{3} & \mathbf{6 8}\end{array}$

${ }^{a}$ Isolated yields. ${ }^{b}$ The reaction was conducted under Ar.

Substrate scope for the cyclization over two steps is shown in Scheme 5 . Fused furan $\mathbf{3 b}$ bearing methoxy groups at the $\mathrm{R}^{1}$ positions resulted in the desired product $\mathbf{5 b}$ in $57 \%$ yield. Similarly, chlorinated substrate $\mathbf{3 c}$ provided naphthofuran $\mathbf{5 c}$ in a higher yield ( $73 \%$ over two steps). Methoxy or methyl substitution at the $\mathrm{R}^{2}$ position led to a decrease in the yields of the corresponding naphthofurans $5 \mathbf{d}$ and $\mathbf{5 e}(25 \%$ and $44 \%$, respectively). These results can be attributed to the cation stabilizing ability of the electron-donating groups at the para-position, which may decrease the reactivity of the 1,2-hydride shift. As expected, furan $\mathbf{3 f}$ bearing an electron-withdrawing chlorine group gave the corresponding naphthofuran $\mathbf{5 f}$ in good yield $(66 \%)$. Finally, we tested the reaction of fused furan $\mathbf{3 j}$ with an isopropenyl group and obtained a dimethylated product $\mathbf{5} \mathbf{j}$ in $72 \%$ yield over two steps. ${ }^{13}$

\section{Scheme 5. Substrate Scope ${ }^{a}$}<smiles>[R]c1ccc(C=C)c(C2=Cc3cccc4c3OC(=C2)C(=O)C=C4)c1</smiles>

3

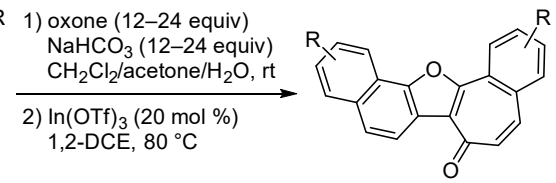

5

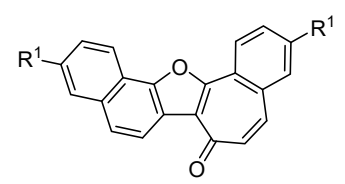

5a: $\mathrm{R}^{1}=\mathrm{H}(64 \%)$

5b: $R^{1}=\mathrm{OMe}(57 \%)$

5c: $\mathrm{R}^{1}=\mathrm{Cl}(73 \%)$

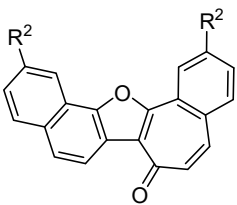

5d: $R^{2}=\mathrm{OMe}(25 \%)$

5e: $R^{2}=\mathrm{Me}(44 \%)$

5f: $\mathrm{R}^{2}=\mathrm{Cl}(66 \%)$

${ }^{a}$ Isolated yields.

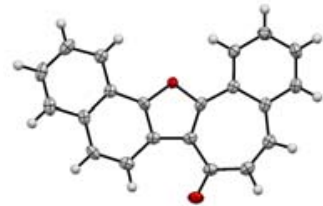

X-ray structure of $\mathbf{5 a}$

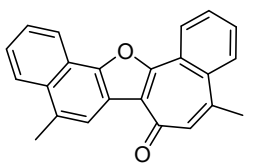

5j $(72 \%)$
In summary, we have developed a novel gold-catalyzed cascade reaction of 1,4-diyn-3-ones in the presence of a pyridine $\mathrm{N}$-oxide. The reaction proceeds through several steps, including gold carbenoid formation and 1,2-alkynyl migration. This approach enabled the direct construction of a benzo[6,7]cyclohepta[1,2-b]furan scaffold with the formation of four bonds in a single operation. Furthermore, a two-step conversion of the resulting furans gave highly fused naphthofuran derivatives. We are currently working on the reaction mechanisms and application studies of this novel methodology.

\section{ASSOCIATED CONTENT}

\section{Supporting Information}

The Supporting Information is available free of charge on the ACS Publications website at DOI: $10.1021 /$ acs.orglett.8b01524.

Experimental procedures, characterization data for all new compounds (PDF). 


\section{Accession Codes}

CCDC 1827398-1827399 and 1827401 contain the supplementary crystallographic data for this paper. These data can be obtained free of charge via www.ccdc.cam.ac.uk/data request/cif, or by emailing data request@ccdc.cam.ac.uk, or by contacting The Cambridge Crystallographic Data Centre, 12 Union Road, Cambridge CB2 1EZ, UK; fax: +44 1223336033.

\section{AUTHOR INFORMATION}

\section{Corresponding Author}

*E-mail: hohno@pharm.kyoto-u.ac.jp

\section{ACKNOWLEDGMENT}

This work was supported by the JSPS KAKENHI (Grant Numbers JP15KT0061 and JP17H03971), the Platform Project for Supporting Drug Discovery and Life Science Research (Platform for Drug Discovery, Informatics, and Structural Life Science) from AMED (Grant Number J17am0101092j0001), and the Hoansha Foundation.

The authors declare no competing financial interest.

\section{REFERENCES}

(1) For selected reviews, see: (a) Nicolaou, K. C.; Montagnon, T.; Snyder, S. A. Chem. Commun. 2003, 53, 551-564. (b) Nicolaou, K. C.; Edmonds, D. J.; Bulger, P. G. Angew. Chem., Int. Ed. 2006, 45, 71347186. (c) Lu, L.-Q.; Chen, J.-R.; Xiao, W.-J. Acc. Chem. Res. 2012, 45, 1278-1293. (d) Ohno, H. Asian J. Org. Chem. 2013, 2, 18-28.

(2) For selected reviews, see: (a) Hashmi, A. S. K.; Hutchings, G. J. Angew. Chem., Int. Ed. 2006, 45, 7896-7936. (b) Kirsch, S. F. Synthesis 2008, 3183-3204. (c) Fürstner, A. Chem. Soc. Rev. 2009, 38, 32083221. (d) Hashmi, A. S. K. Angew. Chem., Int. Ed. 2010, 49, 52325241. (e) Ohno, H. Isr. J. Chem. 2013, 53, 869-882. (f) Dorel, R.; Echavarren, A. M. Chem. Rev. 2015, 115, 9028-9072. (g) Asiri, A. M.; Hashmi, A. S. K. Chem. Soc. Rev. 2016, 45, 4471-4503.

(3) For selected examples, see: (a) Nösel, P.; dos Santos Comprido, L. N.; Lauterbach, T.; Rudolph, M.; Rominger, F.; Hashmi, A. S. K. J. Am. Chem. Soc. 2013, 135, 15662-15666. (b) Wang, L.; Xie, X.; Liu, Y. Angew. Chem., Int. Ed. 2013, 52, 13302-13306. (c) Talbot, E. P. A.; Richardson, M.; McKenna, J. M.; Toste, F. D. Adv. Synth. Catal. 2014, 356, 687-691. (d) Zheng, Z.; Tu, H.; Zhang, L. Chem. Eur. J. 2014, 20, 2445-2448. (e) Ji, K.; Liu, X.; Du, B.; Yang, F. Gao, J. Chem. Commun.
2015, 51, 10318-10321. (f) Zheng, Z.; Zhang, L. Org. Chem. Front. 2015, 2, 1556-1560. (g) Shen, W.-B.; Sun, Q.; Li, L.; Liu, X.; Zhou, B.; Yan, J.-Z.; Lu, X.; Ye, L.-W. Nat. Commun. 2017, 8, 1748. For a recent review, see: (h) Zheng, Z.; Wang, Z.; Wang, Y.; Zhang, L. Chem. Soc. Rev. 2016, 45, 4448-4458. For a related rhodium(I)-catalyzed reaction, see: (i) Liu, R.; Winston-McPherson, G. N.; Yang, Z.-Y.; Zhou, X.; Song, W.; Guzei, I. A.; Xu, X.; Tang, W. J. Am. Chem. Soc. 2013, $135,8201-8204$

(4) Vasu, D.; Hung, H.-H.; Bhunia, S.; Gawade, S. A.; Das, A.; Liu, R.-S. Angew. Chem., Int. Ed. 2011, 50, 6911-6914.

(5) (a) Wang, T.; Shi, S.; Hansmann, M. M.; Rettenmeier, E.; Rudolph, M.; Hashmi, A. S. K. Angew. Chem., Int. Ed. 2014, 53, 37153719. (b) Wang, T.; Shi, S.; Rudolph, M.; Hashmi, A. S. K. Adv. Synth. Catal. 2014, 356, 2337-2342. (c) Wang, T.; Huang, L.; Shi, S.; Rudolph, M.; Hashmi, A. S. K. Chem. Eur. J. 2014, 20, 14868-14871. For a related reaction, see: (d) Zhang, B.; Huang, L.; Yin, S.; Li, X.; Xu, T.; Zhuang, B.; Wang, T.; Zhang, Z.; Hashmi, A. S. K. Org. Lett. 2017, 19, 4327-4330.

(6) Wang, Y.; Zheng, Z.; Zhang, L. J. Am. Chem. Soc. 2015, 137, 5316-5319.

(7) Shiroodi, R. K.; Soltani, M.; Gevorgyan, V. J. Am. Chem. Soc. 2014, 136, 9882-9885.

(8) (a) Barluenga, J.; Tudela, E.; Vicente, R.; Ballesteros, A.; Tomás, M. Angew. Chem., Int. Ed. 2011, 50, 2107-2110. (b) Nagasawa, T.; Taya, K.; Kitamura, M.; Suzuki, K. J. Am. Chem. Soc. 1996, 118, 8949-8950. (c) Marson, C. M.; Walker, A. J.; Pickering, J.; Hobson, A. D. J. Org. Chem. 1993, 58, 5944-5951.

(9) (a) Buccini, M.; Piggott, M. J. Org. Lett. 2014, 16, 2490-2493. (b) Xia, L.; Lee, Y. R. Org. Biomol. Chem. 2013, 11, 6097-6107. (c) Choi, M.; Jo, H.; Kim, D.; Yun, J.; Kang, J.-S.; Kim, Y.; Jung, J.-K.; Hong, J. T.; Cho, J.; Kwak, J.-H.; Lee, H. Arch. Pharmacal. Res. 2016, 39, 618-630. (d) Ha, H.; Debnath, B.; Odde, S.; Bensman, T.; Ho, H.; Beringer, P. M.; Neamati, N. J. Chem. Inf. Model. 2015, 55, 1720-1738.

(10) Piloto, A. M.; Costa, S. P. G.; Gonçalves, M. S. T. Tetrahedron Lett. 2005, 46, 4757-4760.

(11) Nakanishi, K.; Sasamori, T.; Kuramochi, K.; Tokitoh, N.; Kawabata, T.; Tsubaki, K. J. Org. Chem. 2014, 79, 2625-2631.

(12) (a) Kumar, S.; Kim, T.-Y. J. Org. Chem. 2000, 65, 3883-3884. (b) Wakabayashi, R.; Kurahashi, T.; Matsubara, S. Synlett 2013, 24, 2297-2301. (c) Hyodo, K.; Nonobe, H.; Nishinaga, S.; Nishihara, Y. Tetrahedron Lett. 2014, 55, 4002-4005. (d) Oyama, T.; Yang, Y. S.; Matsuo, K.; Yasuda, T. Chem. Commun. 2017, 53, 3814-3817.

(13) For a gold-catalyzed synthesis of seven-membered ring-fused furans, see: Hashmi, A. S. K.; Haufe, P.; Schmid, C.; Rivas Nass, A.; Frey, W. Chem. Eur. J. 2006, 12, 5376-5382. 